\title{
La garantía constitucional en defensa de Derechos colectivos"
}

\author{
Nohora Elena Pardo Posada" \\ Recibido: 5 de junio de 2014. - Revisado: 5 de julio de 2014. \\ Aprobado: 8 de octubre de 2014 .
}

\section{Resumen}

Como suele manifestarse frente al reconocimiento de derechos individuales, son las cartas fundamentales las encargadas de mostrar un nuevo orden y con ello una nueva protección, con el devenir del tiempo se ha introducido una nueva categorización o listado de derechos que han merecido el amparo constitucional, denominados derechos colectivos eje problémico, en el presente artículo se ha formulado el siguiente interrogante: ¿es concordante la garantía constitucional y el desarrollo legal de protección de los derechos colectivos con la naturaleza de estos derechos?

A partir de la formulación del problema arriba citado y bajo una investigación exploratoria, analítica cualitativa con preponderancia del método deductivo, fundado en la revisión de fuentes primarias en su gran mayoría y secundarías respecto a la revisión dogmática de las teorías que apoyan la defensa de los derechos de solidaridad. Los argumentos expuestos buscan demostrar la coherencia del ordenamiento jurídico colombiano en la salvaguardia de los derechos colectivos. El artículo inicia con una revisión doctrinal de la noción de derechos colectivos junto con la distinción entre intereses difusos, la garantía constitucional y el desarrollo legal, por último se presentan las facultades del administrador de justicia en procura del amparo eficaz.

Palabras clave: acción popular, derechos colectivos, constitución, garantía.

"Artículo producto del proyecto de investigación "La revisión eventual de acciones populares", el cual hace parte de los proyectos de investigación institucionales de la Universidad Libre (sede Bogotá); e inscrito en el Grupo de Investigaciones Socio-Jurídicas; línea de investigación de Derecho Público. El citado proyecto está financiado por la Universidad Libre (sede Bogotá).

"'Abogada, magister en Derecho Administrativo de la Universidad Libre. Candidata a magister en derecho procesal y doctora en derecho de la Universidad de Rosario, Argentina. Docente investigador Universidad Libre. Correo electrónico: nohora09@gmail.com 


\title{
The CONSTITUTIONAL GUARANTEE IN DEFENSE OF COLLECTIVE RIGHTS
}

\begin{abstract}
As usually manifests against the recognition of individual rights are the basic charts in charge of showing a new order and thus a new protection with the passing of time have introduced a new classification or list of rights that have deserved constitutional protection, problem-oriented axis called collective rights in this article from which formulated the following question Is the constitutional guarantee consistent legal development and protection of collective rights with the nature of these rights?

From the formulation of the above mentioned problem and under an exploratory research, with qualitative analytical preponderance of the deductive method, based on the review of primary sources for the most part; arguments seeking to demonstrate the consistency of the Colombian legal system in the protection of collective rights will be presented. An article begins with a doctrinal review of the concept of collective rights with the distinction between diffuse interests, constitutional guarantees and legal development and the powers of the judge for effective protection.
\end{abstract}

Keywords: Class action, collective rights, constitution, law, judge.

\section{A garantia constitucional em Defesa dos direitos COLETIVOS}

\section{Resumo}

Como é de costume, frente ao reconhecimento dos direitos individuais, as cartas fundamentais são as encarregadas por mostrarem uma nova ordem e, dessa forma, uma nova proteção. Com o passar do tempo se produziu uma nova categorização, a lista de direitos que merecem o amparo constitucional, denominados direitos coletivos eixo problemático. Portanto, no presente artigo foi formulada a seguinte interrogação: é concordante a garantia constitucional e o desenvolvimento legal de proteção dos direitos coletivos com a natureza destes direitos?

A partir da formulação do problema anteriormente abordado e sob uma investigação exploratória, qualitativa com preponderância do método dedutivo, fundamentado na revisão de fontes primárias, em sua grande maioria, e secundárias sobre a 
revisão dogmática das teorias que apoiam a defesa dos direitos de solidariedade. Os argumentos expostos buscam demonstrar a coerência do ordenamento jurídico colombiano na salvaguarda dos direitos coletivos. $\mathrm{O}$ artigo inicia com uma revisão doutrinal da noção de direitos coletivos junto à distinção entre interesses difusos, a garantia constitucional e o desenvolvimento legal. Por último são apresentadas as faculdades do administrador da justiça: a busca pelo amparo eficaz.

Palavras-chave: Ação popular, direitos coletivos, constituição, garantia.

\section{Introducción}

La conceptualización del sujeto colectivo y por ende de sus derechos es posterior a la del sujeto individual; son las revoluciones las encargadas de presentar al individuo como sujeto de derecho por y en su beneficio; en esta noción sobresale la individualidad, esto es, un ser supremo que puede asumir la forma de dios o príncipe, "entendido como ser total, como ser supraindividual, como legislador y juez anterior $\mathrm{y}$ superior a los seres individuales, a los hombres y mujeres concretos de carne y hueso" (López, 2004, p. 8). Es lo individual en su universalidad lo que da sentido a lo colectivo con las limitaciones que este pueda tener, esto se traduce en la necesidad jurídica de protección del sujeto individual como se observa en las constituciones del Estado liberal con las garantías de igualdad y libertad, con su consecuente participación política desconociendo a la clase (De cabo, 2006, p. 24). No obstante, será el interés general el germen de los derechos colectivos, como bien lo señala López Calera (2004) haciendo alusión a la revolución francesa y a los derechos reconocidos para protección individual. Son sus límites: la soberanía de la nación y ley.

Como suele manifestarse frente al reconocimiento de derechos individuales, son las cartas fundamentales las encargadas de mostrar un nuevo orden y con ello una nueva protección que con el devenir histórico han introducido una nueva categorización o listado de derechos que han merecido el amparo constitucional, para el caso de los derechos colectivos, que son el eje problémico en el presente artículo fundado en el interrogante: ¿es concordante la garantía constitucional y el desarrollo legal de protección de los derechos colectivos con la naturaleza de estos derechos?

A partir de los formulación del problema arriba citado y bajo una investigación exploratoria, analítica cualitativa con preponderancia del método deductivo, y la referencias a fuentes primarias en su gran mayoría y secundarías respecto a la 
dogmática de las teorías fundantes de estos derechos; se presentarán los argumentos que buscan demostrar la coherencia del ordenamiento jurídico colombiano en la salvaguardia de los derechos colectivos, inicialmente en el código civil y con un mayor desarrollo a partir de la vigencia del texto constitucional de 1991 aunado con las leyes que contribuyen a su eficaz amparo.

\section{El sujeto colectivo: ¿otra ficción legal?}

Señala López (2004) que es el individuo quien reconoce, crea y configura lo colectivo fundando el sujeto colectivo por excelencia: el Estado, lo que lleva a afirmar que los sujetos colectivos existen en y por el derecho interno de los Estados. Evidentemente esa existencia es algo distinto de la existencia de las personas naturales. No es posible afirmar que los derechos colectivos corresponden a un ente extraño colectivo con las características comunes de los personas; los derechos colectivos existen como propios de sujetos o personas (p. 45). Nada colectivo tiene sentido sino a través de la participación de los individuos y por su incuestionable servicio a ellos. Lo colectivo es una construcción de los individuos, no es algo "natural", sino "artificial". No es una realidad válida en sí misma y desde luego todo lo colectivo deberá ser tratado exigentemente para evitar que se convierta en una realidad expansiva, que pueda hacer peligrar esa autonomía constitutiva de la dignidad del ser humano.

En palabras de Peña Freire, estos derechos subyacen en la coherencia constitucional, la que lleva a insertar este catálogo de derechos, siendo propios de sistemas que no se encuentran anclados (p. 177).

Ante el proceso de reconocimiento de los derechos colectivos, aparece en la esfera jurídica el derecho colectivo trascendental para la protección estatal: "el derecho de las naciones y de los pueblos a su autodeterminación y a sus recursos naturales" (López, 2004, p. 16), que se mantiene latente a pesar de la globalización y la supranacionalidad de algunas reglas jurídicas, en razón al nacionalismo que se encuentra arraigado a la naturaleza misma del individuo (Ibídem, p. 9). Se requiere un ciudadano del mundo, por lo tanto se hablará de derechos colectivos internacionales y derechos colectivos internos (Habermas, p. 31).

Es así, como la regulación de derechos colectivos, se encuentra entre otros documentos en la Carta Africana de los Derechos del Hombre y de los Pueblos, la Declaración de los deberes fundamentales de los pueblos y de los estados asiáticos, la Declaración de Bangkok y la Declaración Universal de los Derechos del Hombre 
en el Islam, consideradas entre las más importantes (Kowii, 2011), también son protegidos en la declaración de Derechos de las Personas pertenecientes a minorías nacionales, étnicas, religiosas o lingüísticas de 1992, el Acuerdo de la Organización Internacional del Trabajo, relativa a las Tribus y Pueblos Indígenas en los Países Independientes (Convenio 169/1989).

Por su parte, organismos internacionales han mostrado su interés en la temática colectiva y han incluido disposiciones al respecto, en particular la Organización de Estados Americanos (OEA), la Organización para la Unidad Africana (OUA), la Liga de los Estados Árabes, la Organización de Cooperación y Seguridad en Europa (OSCE) y en particular el Acta Final de la Conferencia de Helsinki de 1975, que logró para el año de 1992, el nombramiento del Alto Comisionado en Minorías Nacionales, con el objeto de vigilar el cumplimiento de los derechos de las mismas y prever la aparición de posibles conflictos, así como llevar a cabo las oportunas acciones en la fase inicial (http://www.osce.org/what/tolerance). La Conferencia sobre la Seguridad y la Cooperación en Europa, abierta el 3 de julio de 1973 en Helsinki y continuada en Ginebra del 18 de septiembre de 1973 al 21 de julio de 1975, ha sido clausurada en Helsinki el 1 de agosto de 1975 por los Altos Representantes de la República Federal de Alemania, la República Democrática Alemana, Austria, Bélgica, Bulgaria, Canadá, Checoslovaquia, Chipre, Dinamarca, España, Estados Unidos de América, Finlandia, Francia, Grecia, Hungría, Irlanda, Islandia, Italia, Liechtenstein, Luxemburgo, Malta, Mónaco, Noruega, los Países Bajos, Polonia, Portugal, Reino Unido, Rumania, San Marino, la Santa Sede, Suecia, Suiza, Turquía, la Unión de Repúblicas Socialistas Soviéticas y Yugoslavia. En el numeral 5 del acta se trata el tema del medio ambiente y las formas de cooperación entre los diversos estados.

Si bien no puede atribuirse a un sujeto determinado la existencia de los derechos colectivos, estos son protegidos, amparados y normalizados por disposiciones del orden internacional que buscan la efectiva protección de estos derechos en cabeza de colectivos determinados, sus titulares y los derechos que de ellos emanan no son una ficción legal, por el contrario, a diario adquieren mayor cuerpo y solidez por la importancia que ha ido adquiriendo el colectivo como acreedor de derechos.

\section{Teorías sobre la existencia de lo colectivo}

Diversas teorías fundamentan la existencia de los derechos colectivos, el filósofo y político canadiense Will Kymilcka sostiene que el termino derecho colectivo es 
amplio y se presenta en contraposición con el derecho individual (1996, p. 77), los derechos colectivos son los acordados y ejercidos por los colectivos, siendo distintos a los derechos otorgados a los individuos que forman la colectividad. Los derechos individuales coexisten con los derechos del grupo y se presentan como un logro de las democracias liberales que han contribuido a la coexistencia del multiculturalismo, y a los derechos diferenciados en función a un grupo.

A su turno, Joseph Raz, afirma que:

Un derecho colectivo existe cuando se dan las siguientes tres condiciones. Primera, existe porque un aspecto del interés de los seres humanos justifica que alguna(s) persona(s) esté(n) sujeta(s) a un deber. Segunda, los intereses en cuestión son los intereses de individuos como miembros de un grupo en relación con un bien público y el derecho es un derecho a ese bien público porque sirve sus intereses como miembros de un grupo. Y tercera, ningún interés de un solo miembro de ese grupo respecto a ese bien público es suficiente por sí mismo para justificar que a otra persona tenga que someterse a un deber (López, 2004, p. 42).

Asimismo, la existencia de los derechos colectivos se justifica en tanto sirva a los derechos individuales.

Otro tanto expone el doctrinante español García Amado (2001), quien responde a la pregunta sobre la existencia de derechos colectivos con un depende; y parte para ello de la respuesta que pudiesen dar los positivas, los anti-positivas, los iusnaturalistas, teniendo en cuenta el estatuto ontológico de los grupos que son titulares de derechos colectivos, se distinguen las doctrinas individualistas y colectivistas (p. 182). Entendiendo por tales:

Para las doctrinas individualistas los grupos no son más que el puro agregado, la mera suma de sus miembros, de modo que el grupo como tal no cobra una entidad o sustancialidad independiente y superior a la entidad de sus miembros; es decir, solo formalmente, nominalmente, el grupo existe como tal. Por ejemplo, la familia o la nación no son algo distinto de la mera agregación de sus miembros, no existe la realidad ontológica supraindividual de "la" familia o "la" nación (igual que no existe una realidad ontológica supraindividual y prejurídica de "la" sociedad anónima). Para las doctrinas colectivistas, en cambio, esos grupos titulares de derechos, o al menos algunos de ellos, son algo más que la mera suma o agregación de sus 
componentes, tienen realidad propia, prefiguración necesaria, existencia autónoma, algún género de "vida" que, aun cuando necesite, como condición de posibilidad, de las células o componentes que son los individuos, rebasa, en una unidad superior, la realidad de esos sus componentes. Así, la familia sería algo más que la mera agregación contingente de sus miembros (de los que social o jurídicamente se consideren tales) y la nación algo más que la mera suma de sus ciudadanos (lo que social o jurídicamente se consideren tales). Por tanto, no hay ahí contingencia, sino necesidad ontológica: lo que es una familia o una nación lo determina la realidad de las cosas, no la opinión de nadie, ni siquiera del legislador; y la condición de miembro de una familia o de una nación se posee o no se posee en razón de ciertos datos objetivos que son premorales y prejurídicos, al igual que la condición de célula de un tejido vivo no se adquiere o se pierde por un acto de voluntad o de opinión de las células mismas (Ibídem, p. 188).

Posteriormente se hace la pregunta: ¿cómo se cruzan estas dos clasificaciones? Con las cuatro combinaciones posibles:

Un positivismo individualista, representado por Kelsen. Bajo el enunciado no hay más derechos que los establecidos por el derecho positivo y no hay ningún tipo de ente supraindividual con vida y existencia propia como tal. El positivismo colectivista que parte de la inamovilidad de los jueces del concepto de justicia para el pueblo citando a Hitler: "el suelo sobre el que existe la justicia no puede ser si no el suelo de la existencia de la nación” (Hitler, Regierungserklärung, 23 de marzo de 1933).

Y como teorías antagónicas el antipositivismo individualista, representado por Dworkin, Habermas. Y el antipositivismo colectivista de corte iusfilosófico franquista. Una vez mostradas estas singulares relaciones asevera que:

Si esta clasificación es mínimamente sostenible, su principal utilidad radica en mostrar al incauto que, en cuanto se quiere rebasar el ámbito de lo trivial, el afirmar o negar que existan derechos colectivos obliga ineludiblemente a toda una serie de fundamentaciones y precisiones, aunque sólo sea para no ser ingenuo e inadvertido "compañero de viaje" de algún poco deseable pasajero del mismo tren teórico. En suma, si no se fundamenta con rigor qué quiere decir "derechos" y que quiere decir "colectivos", no se dice en realidad nada tangible o mínimamente relevante y se 
puede ser sospechoso de estar pensando cualquier barbaridad que el propio autor, en su superficial precipitación, ni sospecha (García, p. 197).

La doctrina de manera amplia ha sostenido teorías en contra y a favor de los derechos colectivos (Pérez, 2010), estas últimas parten de la tesis social que considera que es necesario proteger el contexto cultural para el desarrollo de los seres humanos, en su cultura, tradiciones del individuo en donde se desenvuelve, se desarrolla y logrará espacios de reconocimiento social, verbigracia en el órgano colegiado que administra justicia no es la voluntad particular, es el contexto social que llevará a determinada situación, concluye la teoría que los seres humanos los actores de un entorno cultural que debe ser protegido (p. 458). En razón a que la cultura es un bien trasmisible de generación en generación y de allí la importancia de su protección.

Sostiene la tesis colectivista para Van Dyne y Parekh (2005), que los grupos tienen valor por sí mismos y ha esto lo denominan comunalidad (p. 467), que hace parte de la personalidad y la sociabilidad, para el caso de pugna entre derechos individuales y colectivos deben prevaler estos últimos y son derechos colectivos los que identifican al grupo, los cuales imponen el deber de preservación.

La tesis política, por su parte, justifica los derechos colectivos por razones sociales y políticas, el debate toma mayor envergadura por cuanto no es social lo moral o lo cultural el encargado de darle forma al derecho colectivo, son las reivindicaciones de las minorías culturales latentes en las agendas políticas de la democracia en el momento presente, es la protección, la garantía de derechos a las minorías, en este estado, podría considerarse que las minorías encuentran garantizados sus derechos en la formulación del derecho a la igualdad, sin embargo esto no es cierto, pues los grupos étnicos no buscan igualdad, luchan por la reivindicaciones de sus derechos en el plano social y democrático donde se desarrollan. Finaliza la doctrina considerando que estos derechos no son jurídicos sino políticos.

La última tesis a favor de los derechos colectivos, es la tesis de la concreción. Al respecto Levy establece que los derechos colectivos se caracterizan por las exenciones que penalizan prácticas culturales, y para esto presenta como ejemplo, entre otros, a los Amish, que conforme a la interpretación que hacen de la Biblia propenden por un universo alejado del resto del mundo para practicar sus creencias (p. 481), en segundo lugar el autogobierno, reconocimiento de la ley tradicional de la tierra incorporado en el artículo 27 del Pacto civil político de la ONU de 1966, en cuarto 
lugar las protecciones externas autogobierno, representación y reivindicaciones simbólicas protegida en el artículo 7 de la constitución política de Colombia.

La singularidad del colectivo es analizada por López (2000):

Por otra parte, paradójicamente, el liberalismo político considera hoy la pertenencia al grupo como fuente y limitación de los derechos individuales. Así, los Estados europeos e incluso las organizaciones supraestatales de inspiración liberal (Unión Europea) reconocen derechos individuales en razón de los derechos colectivos de un grupo social, cuando toman la categoría política de la "ciudadanía" como fundamento de la titularidad de los derechos y también para la exclusión de los derechos. En última instancia o en gran medida se tienen derechos individuales no por ser "individuo", sino por ser ciudadano de un determinado Estado, por una Staatsangehörigkeit, esto es, por la pertenencia a un grupo, lo cual es una forma de reconocer que los derechos del grupo (derechos colectivos) son anteriores o superiores a los derechos individuales (p. 58).

Finalmente, considera Kymlicka que los derechos colectivos "protegen de la injerencia externa en su forma de ser y de hacer, garantizando su genuina naturaleza y evolución cultural" (p. 114), ha esto se le ha denominado las protecciones externas.

\section{Derechos o intereses difusos}

El vocablo derechos colectivos, intereses difusos, presenta variadas acepciones, lo que conlleva a afirmar la falta de uniformidad en la utilización de este concepto.

La tradicional concepción de derecho subjetivo, interés legítimo e interés simple "que establecen la posición jurídica para exigir una conducta prestacional a otro, para requerir que la administración adecue una conducta y la posibilidad de peticionar" (Meroi, 2006, p. 40). Es quebrantada por la dinámica del derecho y la consagración en los textos constitucionales de derechos de tercera generación (Bazán, 2014) conocidos como derechos colectivos que tienen su sustento en la solidaridad (Ferrer, 2003, p. 3), se pasa del derecho subjetivo a un derecho colectivo sin especificar las condiciones de este último, Andrea Meroi muestra, para introducirse al tema, en su libro Procesos Colectivos, el ejemplo traído por Lorenzetti, que es ilustrativo para conceptualizar el objeto de la investigación que se presenta. Sostiene Víctor Bazán 
que el término generación de derechos requiere un análisis para establecer si léxica, histórica y jurídicamente es correcto o es una arbitrariedad.

En tres literales a partir de un caso hipotético en materia de contaminación ambiental se enseña la multivocidad del término colectivo: el caso narra la lesión a la vida o la salud de una persona $A$, con lo cual se legitima su derecho subjetivo, ella vive en un lugar azotado por la contaminación del aire, vulnerándose así un derecho de incidencia colectiva, común e indivisible, la afectación en la salud y la vida de A y 100.000 personas más cada una con su propio derecho subjetivo, da lugar a la protección de los derechos colectivos, difusos e individuales homogéneos expuesta por la doctrina brasilera (p. 46). Bajo este planteamiento muestra Meroi cómo de un derecho subjetivo se desprenden derechos colectivos.

Por su parte, Montero Aroca en su ponencia titulada el Derecho procesal en el siglo $X X$, se refiere en el subtítulo condicionamientos a la realidad de las partes y su legitimación inicialmente al individuo y de manera extraordinaria a la socialización de la legitimación; fundada en:

La multiplicación de las relaciones jurídicas idénticas, la expansión del consumismo, o la utilización masiva de los medios económicos han puesto las bases para pasar de una consideración individual de las relaciones jurídicas, y con ellas del proceso, a otra en la que cada día adquiere mayor importancia las relaciones que deben calificarse de colectivas, aquí se origina lo colectivo, las relaciones propias de toda sociedad civilizada (p. 469).

Hablar de lo colectivo es referirse a la masa, al conglomerado, a una singularidad de individuos, de donde emergen las diversas categorías, poblaciones, grupos, pero a su vez de la complejidad de las relaciones subjetivas de cada miembro del grupo, que haciendo alusión a Chiovenda como lo señalan Meroi y Morello en las relaciones subjetivas, van envueltos los bienes de vida con la característica de su indivisibilidad pero de uso común verbigracia los recursos naturales, la moralidad pública, la seguridad, el patrimonio arquitectónico. La protección jurídica de estos bienes de vida inicia así:

Con la expansión grupal, como un surtidor, determina la comunicabilidad horizontal de la tutela en favor de todos aquellos sujetos que, apresados en la conexidad 
(diríamos vital) de esa situación común, no juegan en solitario. Se repite con rasgos y efectos idénticos o muy semejantes en seriada (Morello, 2006, p. 38).

La preocupación por lo colectivo no es exclusiva del derecho, en 1968 se publicó en Science, La tragedia de los comunes del ecólogo Garrett Hardin, donde se presenta el ejemplo del ganadero en cuanto ser racional, cada ganadero busca maximizar sus ganancias, tratado por Rozzo (2007) y conocido por los sociólogos, como el dilema de la acción colectiva (para evitar la ruina en un mundo sobrepoblado, las personas deben responder a una fuerza coercitiva que esté más allá de sus psiquis individuales; a un Leviatán, para usar los términos de Hobbes).

Cada hombre está encerrado en un sistema que lo impulsa a incrementar su ganado ilimitadamente, en un mundo limitado. La ruina es el destino hacia el cual corren todos los hombres, cada uno buscando su mejor provecho. Imagine un pastizal abierto para todos. Es de esperarse que cada pastor intentará mantener en los recursos comunes tantas cabezas de ganado como le sea posible. Este arreglo puede funcionar razonablemente bien por siglos gracias a que las guerras tribales, la caza furtiva y las enfermedades mantendrán los números tanto de hombres como de animales por debajo de la capacidad de carga de las tierras. Finalmente, sin embargo, llega el día de ajustar cuentas, es decir, el día en que se vuelve realidad la largamente soñada meta de estabilidad social. En este punto, la lógica inherente a los recursos comunes inmisericordemente genera una tragedia.

En el universo de los economistas según Sabatini (2007), se conoce como el dilema del prisionero:

Dilema del prisionero: si cada prisionero, al confesar el delito que habría perpetrado con un compañero, puede conseguir una condena más breve en comparación con la situación en que no confesara pero sí su compañero, entonces confesará. Y como el compañero actuará con la misma racionalidad, al final la pena agregada de ambos confesos superará en años a la que habrían tenido negando ambos su responsabilidad, esto es, colaborando entre sí. La razón de por qué no colaboran es, en esencia, la desconfianza entre ambos, ya que si uno confiesa y el otro no, el segundo se llevaría una condena superior a la situación en que reconoce su delito. Cada prisionero tiene el incentivo personal de defraudar al otro, aun si hubieran acordado colaborar entre ellos (p. 69). 
Para expresar este universal y pertinaz problema que nos presenta la vida en sociedad, y la razón de fondo en que descansa este fenómeno es lo que universalmente se denomina efecto free rider, para el que tenemos una insuperable expresión chilena: "irse a la cochiguagua".

Se han presentado tres formas de ver en una misma cuestión la vida en sociedad y el ser colectivo que requiere no solo de protección legal sino de atención, respeto y dignidad en un mundo donde lo particular olvida la esencia colectiva.

\section{Rasgos fundantes de un derecho colectivo}

Lo colectivo se opone a lo individual, y en el derecho esto último ha sido objeto de protección legal y constitucional, tanto en el derecho público como en el privado. Como quedó explicado en los párrafos anteriores, lo colectivo no pertenece en particular al sujeto y no es susceptible de división, surge en este momento el interrogante sobre cómo establecer si el bien es colectivo o individual, para dar respuesta a esto, es necesario acudir a sus rasgos fundantes asumiendo lo expuesto por Lorenzetti (2008) en el texto razonamiento judicial donde presenta 8 aspectos de singularidad colectiva:

\begin{tabular}{ll}
\hline ASPECTOS & ALCANCE \\
\hline $\begin{array}{l}\text { Indivisibilidad de los } \\
\text { beneficios }\end{array}$ & Sobre la forma de obrar colectiva o difusa. \\
\hline Uso común & $\begin{array}{l}\text { Para que otros y las generaciones futuras puedan usar el bien, teniendo } \\
\text { en cuenta que el mismo es sustentable; y se puede agotar o consumir } \\
\text { por el uso masivo. }\end{array}$ \\
\hline $\begin{array}{l}\text { No exclusión de } \\
\text { beneficiarios }\end{array}$ & $\begin{array}{l}\text { Por ser colectivos su uso es de todos sin exclusiones, como sucede en } \\
\text { los derechos individuales. }\end{array}$ \\
\hline Estatus normativo & $\begin{array}{l}\text { Citando a Alexy, el derecho colectivo debe estar ordenado en la norma, } \\
\text { como sucede en Brasil, Colombia y Argentina. }\end{array}$ \\
\hline Calificación objetiva & $\begin{array}{l}\text { Unido al estatus normativo, su designación debe estar en el precepto } \\
\text { legal, por cuanto no basta que el bien pertenezca a todos o que sea } \\
\text { indivisible, como por ejemplo los parqueaderos comunes en una zona } \\
\text { residencial. }\end{array}$ \\
\hline Legitimación para obrar & $\begin{array}{l}\text { En estos derechos se encuentran legitimados el defensor del pueblo, } \\
\text { organizaciones y asociaciones, así también cualquier persona. }\end{array}$ \\
\hline $\begin{array}{l}\text { Procedencia de tutela } \\
\text { preventiva }\end{array}$ & $\begin{array}{l}\text { Hay una secuencia de prevenir, restituir y reparar, esto último a su difícil } \\
\text { valoración en dinero. }\end{array}$ \\
\hline
\end{tabular}




\begin{tabular}{ll}
\hline $\begin{array}{l}\text { Resarcimiento a través } \\
\text { de patrimonios de } \\
\text { afectación }\end{array}$ & $\begin{array}{l}\text { Que no pertenece de manera integra a una persona sino a todos los que } \\
\text { se encuentran en las mismas situaciones fácticas y jurídicas. }\end{array}$ \\
\hline $\begin{array}{l}\text { Ubicación en la esfera } \\
\begin{array}{l}\text { social y denominada } \\
\text { colectiva (p. 369) }\end{array}\end{array}$ & $\begin{array}{l}\text { Para el caso no se habla de público o privado, lo esencial es esa nueva } \\
\text { fórmula de protección basada en la solidaridad. }\end{array}$ \\
\hline
\end{tabular}

Fuente: elaboración propia.

\section{Distinción, difusos y colectivos}

La doctrina ha presentado variadas acepciones entre derechos colectivos e interés difusos, partiendo de un criterio de organización para lo cual si los individuos se encuentran organizados se hablará de colectivos y cuando se carece de organización de difusos según Vigorritti (Ferrer, 2003, p. 11), por su parte Giani los distingue por su portador que serán colectivos cuando tiene un ente expotencial del grupo no ocasional; para Dentí son derechos colectivos cuando se predica el carácter corporativo, otra distinción proviene del vínculo jurídico de unión a cargo de Barbosa Moreira, Pelligrini y Montero Aroca, quienes señalan la necesidad de distinción de los intereses colectivos de los plurales, importa los interés comunes del grupo verbigracia familia, sindicato y serán difusos cuando se encuentran vinculados por hechos genéricos y contingentes (p. 12), si bien la doctrina no tiene una unificación frente a la distinción, sí tiene una característica que es reconocida en forma unánime, la cual consideran que su génesis es la supra individualidad, condición que los hace indivisibles (Gutiérrez, p. 88).

Recapitulando, en la categorización entre intereses y derechos colectivos, la doctrina tiende a aceptar el término intereses, sin embargo para la presente investigación se adoptará la expresión derechos colectivos en razón al carácter constitucional que ostentan en el derecho colombiano.

\section{Acepciones de lo colectivo}

Se considera que la acción colectiva parte de la necesidad de tutela frente a derechos de un grupo de personas. Así por ejemplo, Montero Aroca (1994) sostiene que el conflicto plural no es más que la suma de conflictos individuales que se reflejan procesalmente en el fenómeno de la acumulación (p. 62). 
Por su parte Salgado (2011) afirma que el conflicto colectivo se presenta cuando emerge una pretensión grupal insatisfecha de una situación concreta y se reclama su tutela (p. 40).

Se entiende por interés colectivo, 囚aquel que es compartido por un grupo de personas que se encuentran en una misma situación jurídica con respecto a un bien común, necesario disfrutado de manera solidaria y conjunta区 (Meroi, 2008, p. 51), y será interés difuso cuando la comunidad de sujetos es indeterminada, vinculados por las circunstancias fácticas contingentes (Ibídem, p. 52).

El maestro Capeletti (1975), trata lo relativo a los derechos colectivos, propios de la dinámica social del derecho y advierte que son intereses colectivos donde todos y ninguno son titulares de estos derechos (p. 596).

Otra conceptualización de derechos colectivos la realiza la argentina Lidia Garrido (2012), afirma al respecto que los intereses difusos colectivos son de una pluralidad de sujetos y su uso, goce o lesión los afecta por igual. Los intereses difusos colectivos serían los que pertenecen idénticamente a una pluralidad de sujetos en cuanto integrantes de grupos, comunidades ligadas en virtud de goce por parte de cada una de ellas de una misma prerrogativa, de forma tal que la satisfacción de la porción de intereses se extiende a todos, del mismo modo que la lesión afecta simultánea y globalmente a la comunidad.

Considera la doctrina (Zanetti, 2004) que los derechos colectivos en estricto sentido son derechos tras individuales, de naturaleza indivisible donde el titular es un grupo indeterminado (p. 48). Pero no solo la indeterminación es factor para el reconocimiento de derechos colectivos sino también en el disfrute común de un bien, sobre el que recae la pretensión de la acción constituye un derecho colectivo denominado difuso de carácter indivisible para Salgado (p. 42).

A su turno, el código modelo de procesos colectivos para Iberoamérica en su artículo primero establece el ámbito de aplicación de la acción colectiva que se ejercerá para los intereses o derechos difusos que son los supraindividuales, de naturaleza indivisible, de una clase o grupo, y los intereses o derechos individuales homogéneos, constituidos por los derechos subjetivos individuales de un grupo o clase (2002).

En el ámbito latinoamericano, el código brasileño de defensa del consumidor, (Ley 8078/90) consagra: I) Intereses o derechos difusos, transindividuales de naturaleza indivisible, de los que surgen titulares indeterminados y ligados por circunstancias de hecho; II) Interés difusos o transindividuales de naturaleza indivisible, de los que surgen titulares indeterminados y ligados por circunstancias de hecho; 
II) Intereses o derechos individuales homogéneos, así entendidos los concurrentes en origen común. Normatividad considerada como una de las más avanzadas en esta temática en el continente.

\subsection{La garantía constitucional: la acción popular - normatividad colectivista}

La constitución de 1991, entre intereses colectivos e intereses difusos, delimitando los primeros a un grupo organizado y los segundos a comunidades indeterminadas, en el texto constitucional indistintamente se establece el término colectivos.

Frente a la legitimidad por activa, ha señalado el máximo tribual constitucional en una interpretación de la norma que las acciones populares protegen a la comunidad en sus derechos colectivos y por lo mismo, pueden ser promovidas por cualquier persona a nombre de aquella cuando ocurra un daño a un derecho o interés común (C-const, C- 215/99.).

Los antecedentes constitucionales datan en la Comisión Primera de la Asamblea Nacional Constituyente, con base en el proyecto presentado por los delegatarios Guillermo Perry Rubio, Horacio Serpa Uribe y Eduardo Verano de la Rosa, donde se afirmó:

Casi todos los proyectos que contienen reformas integrales a la constitución, proponen la consagración de las acciones populares como remedio colectivo frente a los agravios y perjuicios públicos, como un derecho de defensa de la propia comunidad. Mediante las acciones populares cualquier persona perteneciente a un grupo de la comunidad está legitimada para defender al grupo afectado por unos hechos o conductas comunes, con lo cual protege su propio interés (...).

De otra parte, subsisten acrecentadas las razones que en la historia de las instituciones jurídicas, justificaron en su momento la aparición de estas acciones para defender intereses de la comunidad... Todo ello con el fin de legitimar a cualquier persona para actuar en defensa de la sociedad, protegiendo así tanto intereses que la doctrina engloba hoy bajo el significativo rótulo de "difusos", como también los propios del actor (Gacetas No. 45 y 48).

El conjunto de derechos e intereses colectivos susceptibles de ser protegidos en sede judicial se funda inicialmente en la constitución política (Art. 88), sin embargo 
su desarrollo y determinación concreta fue realizada por el legislador (ley 472/98, art. 4) que enlista como tales a:

(i) Al goce de un ambiente sano; (ii) la moralidad administrativa; (iii) la existencia del equilibrio ecológico y el manejo y aprovechamiento racional de los recursos naturales para garantizar su desarrollo sostenible, su conservación, restauración o sustitución. Así como la conservación de las especies animales y vegetales, la protección de áreas de especial importancia ecológica, de los ecosistemas situados en las zonas fronterizas, al igual que los demás intereses de la comunidad relacionados con la preservación y restauración del medio ambiente; (iv) el goce del espacio público y la utilización y defensa de los bienes de uso público; (v) la defensa del patrimonio público; (vi) la defensa del patrimonio cultural de la Nación; (vii) la seguridad y salubridad públicas; (viii) el acceso a una infraestructura de servicios que garantice la salubridad pública; (ix) la libre competencia económica; (x) el acceso a los servicios públicos y a que su prestación sea eficiente y oportuna; (xi) la prohibición de la fabricación, importación, posesión, uso de armas químicas, biológicas y nucleares, así como la introducción al territorio nacional de residuos nucleares o tóxicos; (xii) el derecho a la seguridad y prevención de desastres previsibles técnicamente; (xiii) la realización de las construcciones, edificaciones y desarrollos urbanos respetando las disposiciones jurídicas, de manera ordenada, y dando prevalencia al beneficio de la calidad de vida de los habitantes; $y$ (xiv) los derechos de los consumidores y usuarios.

En este estado, se considera como interés colectivo el que pertenece a todos los miembros de una colectividad determinada. En la exposición de motivos correspondiente al proyecto de ley de acción popular se expresó:

Es así como, de acuerdo con la naturaleza de los intereses amparados, las acciones populares pueden formularse en defensa de la calidad sobre los bienes y servicios que le son ofrecidos y prestados; a disfrutar de un ambiente sano; a que se prevengan y controlen los factores de deterioro ambiental; a que no se fabriquen, importen ni usen en el territorio nacional armas químicas, biológicas o nucleares; a que se proteja y conserve la integridad del espacio público y su destinación al uso común; el derecho a la paz y todos aquellos inherentes a una convivencia pacífica, democrática y participativa; los que asisten a las comunidades indígenas y demás grupos étnicos a orientar y desarrollar sus actividades, de conformidad con sus tradiciones. Además, llama la atención la definición de intereses colectivos como la administración clara, transparente y eficaz de la cosa pública; la protección del patrimonio 
cultural y el acceso garantizado a una infraestructura adecuada de servicios públicos con fundamento en el principio de solidaridad social" (Congreso de la República. Proyecto de ley No. 69 de 1993).

La génesis de las acciones populares puede considerarse en dos etapas, inicialmente con fines abstractos, por defender el orden jurídico, esto es la legalidad y la constitucionalidad de los actos jurídicos de carácter legislativo y administrativo, y una segunda etapa con fines concretos, en protección del interés colectivo de un sector de la comunidad amenazada o vulnerada en sus derechos.

Desarrollo de la segunda etapa el código civil regula las acciones populares clasificadas en dos grandes grupos: a) Protección de bienes de uso público (entre otros, artículos 1005, 1006, 1007, 2358 y 2360), conducentes a preservar la seguridad de los transeúntes y el interés de la comunidad respecto de obras que amenacen causar un daño ; y b) Acción por daño contingente (artículos 2359 y 2360), que puede derivarse de la comisión de un delito, la imprudencia o negligencia de una persona, que pongan en peligro a personas indeterminadas.

A su turno, se encuentran las acciones populares reguladas por leyes especiales: Defensa del consumidor (Decreto Ley 1480 de 2012 Estatuto del Consumidor); Espacio público y ambiente (La Ley 9 de 1989 (Art. 8) -Reforma Urbana-, que remite a la acción popular establecida en el Código Civil (Art. 1005); competencia desleal (Ley 45 de 1990), relativa a la intermediación financiera, normas que en materia de la actividad aseguradora, hacen el reenvío a las disposiciones de protección de las personas perjudicadas con esas prácticas contenidas en el Decreto Ley 3466 de 1982; protección al consumidor financiero ley 1328 de 2009, Reglamentado por el Decreto Nacional 2241 de 2010 que crean la figura del defensor financiero; el medio de control de protección de los derechos e intereses colectivos (Ley 1437/11, art. 144). Cualquier persona puede demandar la protección de los derechos e intereses colectivos para lo cual podrá pedir que se adopten las medidas necesarias con el fin de evitar el daño contingente, hacer cesar el peligro, la amenaza, la vulneración o agravio sobre los mismos, o restituir las cosas a su estado anterior cuando fuere posible; la protección al consumidor aéreo (resolución 1209 de 2015), mediante la cual la aeronáutica civil brinda protección y garantía para quienes hacen uso de los servicios aéreos en el país en temas como el retracto y su ejercicio dentro de las 48 horas siguientes a la compra del tiquete evento, el desistimiento en trayectos 
nacionales en un término de hasta 8 días antes del vuelo y 15 días en el caso de los vuelos internacionales; y la regulación para el retardo de los itinerarios.

\title{
7. Notas distintivas de la acción popular
}

Su carácter preventivo, la amenaza de un derecho colectivo legítima su protección por el operador judicial, tinte este característico de la acción popular se busca proteger y evitar el daño que para el caso del derecho colectivo puede ser irreparable en la mayoría de las ocasiones, en palabras de la Corte Constitucional este carácter emerge:

\begin{abstract}
Desde los más remotos y clásicos orígenes en el derecho latino fueron creadas las acciones populares para prevenir y precaver la lesión de bienes y derechos que comprometen altos intereses cuya protección no siempre supone un daño. En verdad, su poco uso y otras razones de política legislativa y de conformación de las estructuras sociales de nuestro país, desdibujaron en la teoría y en la práctica de la función judicial esta nota de principio. Los términos del enunciado normativo a que se hace referencia, no permiten abrigar duda alguna a la Corte sobre el señalado carácter preventivo. Se insiste ahora en este aspecto, en virtud de las funciones judiciales de intérprete de la constitución que corresponden a esta corporación. (M.P. Fabio Morón Díaz).
\end{abstract}

Es de destacar que en la actualidad, las acciones populares no comportan el resarcimiento pecuniario en favor de quien promueve el reclamo judicial de un interés colectivo; si bien es cierto, en su regulación originaria se establecía un reconocimiento de los gastos en que incurriera la persona que actuaba en defensa del interés público, se prescindió de ella por mandato legal del año 2010 (Ley 1425), bajo el argumento que el incentivo había perdido su razón de ser y había convertido a las acciones populares en verdaderos negocios (Gaceta del congreso, 2010, p. 2), lo que demostraba el distanciamiento del carácter altruista y solidario inherente a la acción popular.

En definitiva, hay que observar que estas acciones tienen una estructura especial que la diferencia de los demás procesos litigiosos, en cuanto no son en estricto sentido una controversia entre partes que defienden intereses subjetivos, sino que se trata de un mecanismo de protección de los derechos colectivos prexistentes radicados para efectos del reclamo judicial en cabeza de quien actúa a nombre de 
la sociedad, pero que igualmente están en cada uno de los miembros que forman la parte demandante de la acción judicial.

\title{
7.1. Requisitos de procedencia
}

Los requisitos para la procedencia de la acción popular se limitan a: a) que se instaure, en general, por cualquier persona, b) que esté de por medio la vulneración de derechos o intereses colectivos, c) que dicha vulneración sea ocasionada por un acto, una acción o una omisión de una entidad pública o de personas privadas que desempeñen funciones administrativas.

Con la entrada en vigencia del código de procedimiento administrativo y de lo contencioso administrativo se estableció como requisito de procebilidad la presentación de una petición ante la autoridad presuntamente vulneran te del derecho colectivo, según reza:

\begin{abstract}
Antes de presentar la demanda para la protección de los derechos e intereses colectivos, el demandante debe solicitar a la autoridad o al particular en ejercicio de funciones administrativas que adopte las medidas necesarias de protección del derecho o interés colectivo amenazado o violado. Si la autoridad no atiende dicha reclamación dentro de los quince (15) días siguientes a la presentación de la solicitud o se niega a ello, podrá acudirse ante el juez. Excepcionalmente, se podrá prescindir de este requisito, cuando exista inminente peligro de ocurrir un perjuicio irremediable en contra de los derechos e intereses colectivos, situación que deberá sustentarse en la demanda (Art. 144).
\end{abstract}

\subsection{Alcance}

El Consejo de Estado ha señalado que en virtud de lo dispuesto en Ley la 472 (Art. 38), la acción popular no es procedente en aquellos eventos en los que se pretenda por particulares o por una colectividad la satisfacción de intereses económicos, no obstante lo anterior, a través de la acción popular únicamente es posible condenar al pago de perjuicios cuando la favorecida con estos sea una entidad pública que tenga a su cargo la protección del derecho o interés colectivo y no haya sido culpable de su transgresión, esto es, en ningún caso procede el pago de perjuicios a favor de particulares, como se indicó. Ahora bien, según lo dispone la 
citada norma, la aludida condena al pago de perjuicios solo procederá en el evento de que se profiera sentencia que acoja las pretensiones del demandante (Consejo de Estado, auto: 201923005001-23-31-000-2006-02720-01. S. Buitrago).

La jurisprudencia ha reconocido la existencia de un límite objetivo según el cual cuando aparecen nuevas circunstancias de hecho o elementos de prueba de los cuales se advierta la existencia de una amenaza o vulneración de un derecho colectivo, la sentencia que se haya dictado en una acción popular tan solo hará tránsito a cosa juzgada con carácter relativo, siendo procedente el ejercicio de dicha acción frente a esa nueva realidad fáctica (Consejo de Estado, exp. 2005-00240 AP. R. Correa).

\section{Conclusiones}

La salvaguarda y defensa de los derechos colectivos por el ámbito legal, muestra los avances, la constante evolución y transformación del derecho que parte del amparo individual al reconocimiento de una denominación de derechos que pertenecen al colectivo, siendo imposible la atribución de estos derechos a la persona individualmente considerada.

El accionar del juez se encuentra limitado por la constitución y la ley, para el caso de marras su deber consiste en adoptar las medidas que sean necesarias para restablecer las cosas al estado anterior a la vulneración del derecho o del interés. Los límites normativos se precisan en evitar el daño contingente, hacer cesar el peligro, la amenaza, la vulneración o agravio sobre los derechos e intereses colectivos, o restituir las cosas a su estado anterior si ello fuere posible.

En concordancia le corresponde al juez adoptar las órdenes de hacer o de no hacer, definiendo de manera precisa la conducta a cumplir, condenar al pago de perjuicios cuando se haya causado daño y, en fin, exigir la realización de las conductas necesarias para volver las cosas al estado anterior a la vulneración del derecho o del interés colectivo, cuando fuere físicamente posible, de manera tal que se garantice la eficacia de los derechos vulnerados, como lo exige el artículo 88 constitucional.

Indudablemente, en la sentencia que ampara los derechos colectivos, el juez está facultado para adoptar las medidas que, conforme a la situación fáctica probada, sean conducentes y pertinentes para obtener la protección de dichos derechos. Lo anterior guarda coherencia con el artículo 2 de la constitución política al establecer que las autoridades de la República están instituidas para proteger a todas las personas residentes en Colombia, en su vida, honra, bienes, creencias, y demás 
derechos y libertades, y para asegurar el cumplimiento de los deberes sociales del Estado y de los particulares.

Como bien lo expresa el Consejo de Estado, la protección de los derechos colectivos exige, antes que la evocación de un enunciado formal de prevalencia de los derechos colectivos, su plena eficacia material. Y a ese objetivo debe orientarse imperiosamente la actividad de las autoridades, incluyendo la tarea del juez de la acción popular.

Para la eficaz protección del derecho colectivo las autoridades encargadas de su protección deben cumplir con los deberes que les son exigibles. Al juez asumir competencia corregirá eficazmente las irregularidades que lesionan principios rectores de la actividad administrativa, conjurando oportunamente hechos u omisiones capaces de generar daños colectivos, con el fin de superarlos, restituyendo las cosas a su estado anterior, si ello resulta posible, como lo ordena la normatividad.

Por lo tanto, la acción desde su origen constitucional y legal otorga al juez de amplios poderes posibilitando la adopción de las medidas que sean necesarias para restablecer las cosas al estado precedente a la vulneración del derecho o interés colectivo, en una oportunidad anterior ya se había pronunciado sobre la materia manifestando en la acción popular se presenta una co-existencia de los principios referidos, en virtud de la cual, una vez iniciado el proceso y fijados los elementos fáctico y jurídico de la demanda por parte del actor popular, el juez queda suficientemente investido para decretar de oficio pruebas y medidas cautelares en procura de la protección de los derechos colectivos, dentro de los límites que le impone el principio de congruencia.

Finalmente, la preocupación por los derechos colectivos no es exclusiva del operador jurídico, sociólogos y economistas han detenido su actividad habitual para pronunciarse sobre la necesidad de reconocimiento y protección de esta clase de derechos; por su parte la doctrina ha contribuido en gran medida a este reconocimiento, al aportar elementos identificadores de lo denominado colectivo $\mathrm{y}$ su adherencia al sujeto individual como parte fundante de estos derechos sin que puedan atribuirse a la singularidad del sujeto su existencia.

Las organizaciones internacionales han prohijado en sus reglamentos disposiciones para defender y proteger los derechos de solidaridad de las agresiones externas que los colectivos puedan sufrir; otro tanto han efectuado los Estados, quienes regulan al interior y de manera específicas en sus constituciones la incursión en este nuevo sujeto de derecho que rompe con el tradicional esquema individual. 
Para el caso colombiano, si bien no es atribuye a la constitución del 1991 la salvaguarda de estos derechos en razón a su regulación desde el código civil, debe reconocerse que es al texto constitucional quien ha incrustado la doctrina nacional e internacional a la hermenéutica del artículo 88 constitucional, a la ley 478 de 1998 elementos jurídicos fundantes de la garantía constitucional de protección de los derechos colectivos; que en la actualidad son objeto de regulación verbigracia en protección al consumidor.

En suma, la garantía constitucional ha contribuido en gran medida a volver sobre lo colectivo procurando su debida protección legal, al desarrollo del principio de solidaridad y a considerar que en la esfera fáctica el interés general debe prevalecer sobre el individual.

\section{Referencias}

Ansuátegui, F. (2004). Una discusión sobre derecho colectivo. España: Dykinson.

Bazán, V. (2014). Derechos económicos, sociales y culturales. Cómo se protegen en América Latina y en Europa. Argentina: Astrea.

Cappelletti, M. (1975). La protection a®intérêts collectifs et de groupe dans le procès civile -Métamorphoses de la procédure civile-, Revue Internationale de Droit Comparé- RICD. Conferencia pronunciada el 14 de marzo de 1975 ante la Asamblea General de la Sociedad de Legislación Comparada.

Código modelo de procesos colectivos para Iberoamérica. (2002). Caracas, Venezuela.

Código Civil Colombiano. (s.f.). Recuperado de http://www.secretariasenado.gov.co/senado/ basedoc/codigo_civil.html

Consejo de Estado. Sección Quinta. Auto: 201923005001-23-31-000-2006-02720-01/14. S. Buitrago.

Corte Constitucional. C-240/99, M. Sachica.

De Cabo, M. (2006). Teoría Constitucional de la solidaridad. Barcelona: Marcial Pons.

Ferrer, E. (2003). Juicio de Amparo e interés legítimo: la tutela de los derechos colectivos y difusos. Breviarios Jurídicos. México: Editorial Porrúa.

García, J. (2001). Sobre derechos colectivos dilemas, enigmas, quimeras. Una discusión sobre derechos colectivos. Coordinado por Francisco Javier Ansuátegui Roig.

Garrido, L. (s.f.). Los daños colectivos y la reparación. Disponible en www.juridicas.unam. $\mathrm{mx} /$ publica/librev/rev/vniver/cont/.../cnt14.pdf

Gutiérrez, C. (2011). La tutela jurisdiccional de los intereses supraindividuales: difusos y colectivos. 
Ley 427 de 1998. (6 de agosto de 1998). Por la cual se desarrolla el articulo 88 de la Constitución Politica de Colombia en relación con el ejercicio de las acciones populares y de grupo y se dictan otras disposiciones. Diario Oficial No. 43.357, de agosto 6 de 1998.

Ley 1245. (29 de diciembre de 2010). Por medio de la cual se derogan artículos de la Ley 472 de 1998 Acciones Populares y Grupo. Diario Oficial 47937 de diciembre 29 de 2010.

López, N. (2004). ¿ Hay derechos colectivos? Individualidad y sociabilidad en la teoría de los derechos. España: Editorial Ariel.

Lorenzetti, R. (2009). Razonamiento Judicial. Fundamentos de Derecho Privado.

Kowii, A. (2011). Interculturalidad y diversidad. Ecuador: Corporación Editora Nacional. Ebrary collections. Disponible en http://site.ebrary.com/lib/bibliounilibresp/ Doc?id=10877554\&ppg=111

Kymilcka. W. (1996). Ciudadanía multicultural. Paidós estado y sociedad.

Meroi, A. (2008). Derechos colectivos. Argentina: Rubinzal.

Morello, A. (2010). La tutela de los intereses difusos en el derecho argentino: legitimaciones, medidas cautelares, trámite y efectos del amparo colectivo. Argentina: Librería Editora Platense.

Montero, J. (2003). El derecho procesal en el siglo XX. Disponible en http://biblio.juridicas. unam.mx/libros/1/114/13.pdf

Montero, J. (1994). La legitimación en el proceso civil. Madrid: Civitas.

Pérez, O. (2005). Pluralismo cultural y derecho de las minorias. Dykinson.

Resolución 1209. (Mayo de 2015). Aeronáutica Civil.

Rozzi, R. (2007). Legislando la relación sociedad-naturaleza. Revista Ambiente y Desarrollo de CIPMA, 23(1). Santiago de Chile.

Salgado, J. (2011). Tutela Individual homogénea. Buenos Aires: Astrea.

Sentencia: EXP 2005-00240/08, R. Correa.

Sentencia: 2018698 25000-23-27-000-2001-90479-01/14. M. Velilla.

Sentencia: SU-067/93. C. Angarita.

Zanetti, H. (2004). Derechos difusos Lato Sensu, VV.AA.: La tutela de los derechos difusos, colectivos e individuales homogéneos. México: Instituto Iberoamericano de Derecho Procesal. 1437. (18 de enero de 2011). Por la cual se expide el Código de Procedimiento Administrativo y de lo Contencioso Administrativo. Diario Oficial 47.956 de enero 18 de 2011. 